\title{
Control of the first wave of COVID-19: Some economic freedom-related success factors
}

\author{
Juan Dempere \\ Department of Business, HCT, \\ United Arab Emirates \\ jdempere@hct.ac.ae \\ ORCID 0000-0002-5036-2355
}

\begin{abstract}
This research aims to study some economic freedom-related factors with explanatory power on the countries' success in controlling the first wave of COVID-19. Our selected factors include the economic, business, labour, monetary, trade, investment, financial, press, human, and personal freedom indexes. Our dependent variables include the government's daily average stringency index, the outbreak response time, the daily average of cases per million, the daily average of deaths per million, and the daily average of COVID19 tests per thousand. We find that countries with superior degrees of freedom suffered a more severe impact of the outbreak as confirmed by the highest daily average of cases and deaths per million. This severe impact happened while governments had a controllable response to the outbreak as verified by the lowest daily average stringency index. However, these countries were more effective at controlling the first wave of COVID-19 as measured by the shorter outbreak response time and a higher daily average of COVID-19 tests per thousand.
\end{abstract}

Keywords: COVID-19, Heritage Foundation, economic freedom, Cato Institute, pandemic.

JEL Classification: P5, I0, H0, E6

\section{INTRODUCTION}

The COVID-19 outbreak constitutes the most severe global crisis of the 21st century after the 9/11 terror attacks and the 2008 financial crisis. However, since the outbreak is not under control yet, it will probably represent one of the most challenging crises in modern human history. The pandemic will produce significant long-term political, economic, and social effects that are difficult to anticipate. For some countries, this crisis has already produced unprecedented statistics. For example, Lambert (2020) informs that more Americans have died of COVID-19 than the number of American lives lost in World War I $(116,516)$, in the 1968 pandemic $(100,000)$, in the Vietnam conflict $(58,220)$, in the Korean War $(36,574)$, and all US military conflicts in the Middle East $(9,353)$. 
The International Labour Organization (ILO 2020) estimated a decline in working hours of about 10.7 percent in the second quarter of 2020 compared to the same quarter in 2019, which is equivalent to 305 million full-time jobs. The World Bank (WB 2020) estimates a 5.2 percent contraction in the global Gross Domestic Product (GDP) for 2020, considered the deepest global recession in decades. The World Bank also estimates that most countries will enter into a recession in 2020, resulting in a per capita income contraction of about 7 percent for the most substantial fraction of countries globally since 1870 . The United Nations (UN 2020) states that the COVID-19 outbreak has led to the most massive disruption of education ever, with at least 40 million children worldwide missing education in their critical pre-school year. These are just a few unprecedented records set by the COVID-19 crisis.

This article aims to study some economic freedom-related factors that may explain the success of some countries at controlling the first wave of COVID-19. Our sample of sixty-five countries was analysed using generalized linear models, generalized binomial models, and weighted least squares models. Our dependent variables include the government's daily average stringency index, the outbreak response time, the daily average of cases per million, the daily average of deaths per million, and the daily average of COVID-19 tests per thousand. We find that countries with superior degrees of freedom suffered more severe effects of the outbreak as measured by higher daily averages of cases and deaths per million. These grave effects resulted from a softer government pandemic response as verified by a lower daily average stringency index. However, these countries could control the outbreak more effectively as evidenced by a shorter outbreak response time and a higher daily average of COVID-19 tests per thousand. We also find that the probability of a country controlling the COVID-19 successfully is negatively related to its business freedom, but positively related to its monetary and press freedom. The limitations of our study include, but are not limited to, differences in how countries record COVID-19 deaths, differences in testing efforts, differences in health services, possibly unreliable data from countries with tightly controlled political systems, and many demographics variables affecting the pandemic spread like average age, population density, urban versus rural population, age structure, etcetera. The rest of this article is organized as follows: literature review, data and methodology, results, interpretations and limitations, conclusions, and references.

\section{LITERATURE REVIEW}

\subsection{COVID-19 outbreak}

Previous research works on COVID-19 are primarily focused on medical sciences and healthcarerelated disciplines. A few academic articles have used similar dependent or independent variables as the ones considered in this study. Erdem (2020) studies investors' reaction to coronavirus data announcements from seventy-five countries controlling their scores on the Freedom House's 2019 freedom index. This index is based on the political rights and civil liberties exiting in each country. He finds significant negative effects in stock markets resulting from the number of cases per million. He also finds that announcements about increases in the number of cases per million generates lower stock market returns and volatiles in less-free countries. Herren et al. (2020) study some factors affecting non-pharmaceutical interventions (NPIs) defined as the efforts to decrease social mobility to reduce the spread of the COVID-19. They find that GDP per capita, country-specific outbreak trajectory, democracy index are relevant factors in determining a given population's acceptance of NPIs. Mazzucchelli et al. (2020) study some political-risk factors with significant explanatory power on the variability of COVID-19 mortality among European countries. They analyze the democracy index and its components, including each country's political system and corruption index. They find that the democracy index and its components, the political system, and the corruption index all have a statistically significant and positive relationship with the COVID-19 mortality. In other 
words, significant scores on democracy indexes have associated high scores on pandemic mortality. Alon, Farrell, and Li (2020) compare the China's COVID-19 response and Taiwan's using a multi-case approach. They find that transparent and open communications, a characteristic of democratic countries, allowed Taiwan's response to be more effective and less invasive than China's. They argue that the slow response to the epidemic of politicians in Italy, Spain, the US, and other democracies has caused heavy costs to their countries and the world. They also state that in democracies, voters distrust politicians in responding to crises, which increases the difficulty of implementing any policies.

\subsection{Economic freedom}

Regard our independent variables, some previous studies could find evidence supporting some relationships also identified in this article. Yevdokimov et al. (2018) study the influence of economic freedom on macroeconomic stability. They find that countries with open institutions have democratic political systems and high GDP per capita. They also find a positive and significant relationship between economic freedom and macroeconomic stability. Bjørnskov, C. (2016) studies the relationship between the degree of capitalism as measured by economic freedom, and the risk and characteristics of economic crises. He finds that the magnitude of the economic contraction during an economic crisis measured by the peakto-trough ratio of real GDP per capita has a negative and significant relationship with the initial economic freedom. Peev and Mueller (2012) study twenty-four post-communist economies over the period 1990-2007 and find that trade and monetary freedom, as well as freedom from corruption indexes, are the most significant variables that can explain economic growth for the studied countries. Finally, Cepaluni et al. (2020) study the relationship between political institutions and deaths during the first 100 days of the COVID-19 pandemic. They find that more democratic political institutions experienced more and sooner deaths per capita than less democratic institutions.

No previous research article has studied economic freedom-related factors that may explain countries' success in controlling the first wave of COVID-19. Therefore, this study's original contribution is to determine the explanatory power of freedom-related variables regarding outbreak control. Our results may be valuable for multilateral entities and international non-governmental organizations when designing aid policies to fight the pandemic.

\section{DATA \& METHODOLOGY}

Our sample includes countries with available data for our dependent and independent variables. We excluded countries with a population of less than a quarter-million people to avoid outliers in our dependent variables. We also excluded countries with internal conflicts (Libya, Yemen, and Syria) and countries with external political conflict affecting their capacity to control the COVID-19 outbreak (Iran and Venezuela). Our final sample consists of one hundred and fifty-six countries.

Our dependent variables include the government's daily average stringency index (DV1), the outbreak response time (DV2), the daily average of cases per million (DV3), the daily average of deaths per million (DV4), and the daily average of COVID-19 tests per thousand (DV5). Like Erdem (2020) and Herren et al. (2020), the data of our dependent variables were compiled by Hannah et al. (2020) and retrieved from Our World in Data. The starting outbreak date varies from country to country; however, no country has a beginning date earlier than December 31, 2019. Nevertheless, all countries in our sample have the same ending date on July 10, 2020. Our last dependent variable is a binary variable (DV6) that takes the value of one if the graph of the 5-day moving average of the reported daily new cases is concave down with only one maximum and a partially symmetric shape (kurtosis between -3 and +3 ). The same dependent variable equals zero if the same graph shows a growing linear, exponential, or logarithmic trend. Countries 
experiencing a second wave of COVID-19 were excluded from this analysis. This narrow selection criterion produced a subsample of sixty-five countries that we analyzed using generalized binomial models explained below.

The government's daily average stringency index is a combined measure based on nine response scores, including but not limited to, school closures, workplace closures, and travel bans. This variable is measured on a scale from zero to one hundred, where one hundred represents the strictest government reaction to the COVID-19. The daily average for this stringency index is calculated from the first reported case's date until July 10, 2020. The outbreak response time is the number of days between the first reported case's date and the date of the first maximum of the curve resulting from the 5-day moving average of the daily new cases. This methodology is similar to that of Bjørnskov, C. (2016), who finds that the recovery time measured by the peak-to-trough ratio of real GDP per capita is negatively related to initial economic freedom, although he studies crises of economic nature. The daily average of cases and deaths per million and tests per thousand were determined by dividing the total cases and deaths per million, and tests per thousand by July 10,2020, over the number of days since the first case's date. The mortality rate is calculated by dividing the total deaths per million on July 10, 2020, by the total cases per million on that date.

Data for our independent variables were retrieved from the individual components of the 2020 Index of Economic Freedom (IV1) published by the Heritage Foundation (HF 2020.) This index is based on twelve quantitative factors, grouped into four broad categories, including the rule of law (which includes property rights, government integrity, and judiciary effectiveness) and government size (which includes government spending, tax burden, and fiscal health). The other two categories are regulatory efficiency (which includes business freedom, labor freedom, monetary freedom), and open markets (which includes trade freedom, investment freedom, and financial freedom). Out of the four classes listed above, only two measuring different types of freedom were analyzed in this study. These freedom-related independent variables include the business freedom index (IV2), the labor freedom index (IV3), the monetary freedom index (IV4), the trade freedom index (IV5), the investment freedom index (IV6), and the financial freedom index (IV7).

The business freedom index measures the degree of constraining imposed by national regulatory and infrastructure environments to businesses' efficient operation. This index includes several factors associated with starting and closing a business: the procedures, time, cost, minimum capital, and recovery rate. The index also includes the procedures, time, and cost of obtaining a license and getting electricity. Each of these elements is converted to a scale of zero to one hundred, and their average is the country's business freedom score.

The labor freedom index includes several elements of the legal and regulatory framework of a country's labor market. The index includes the ratio of the minimum wage to the average value added per worker, hindrance to hiring additional workers, rigidity of hours, difficulty of firing employees, legally required notice period, mandatory severance pay, and labor force participation rate. These factors are transformed into a scale of zero to one hundred, and their average is the labor freedom score.

The monetary freedom index quantifies inflation and government activities that may result in distorted prices of goods and services. The index comprises the most recent three-year weighted average inflation rate and a qualitative judgement about the impact of governments' controls or subsidies aimed at manipulation of market prices. The trade freedom index measures the impact of tariff and non-tariff barriers on imports and exports of goods and services. This index includes the trade-weighted average tariff rate and a qualitative assessment for non-tariff barriers.

The investment freedom index measures the quality and quantity of national restrictions to the flow of investment capital, such as restrictions on access to foreign exchange, payments, transfers, and capital transactions. This index is calculated based on an ideal national score of one hundred, reflecting a scenario 
of people and companies allowed to allocate their resources in and out of economic activities, both nationally and internationally, without any government restriction. Points are deducted from this perfect score for every restriction associated with the national treatment of foreign investment, foreign investment code, restrictions on land ownership, sectorial investment restrictions, expropriation of investments without fair compensation, foreign exchange controls, and capital controls.

The financial freedom index measures the degree of a country's banking efficiency and independence from government control and interference in the financial sector. This index quantifies five broad areas, namely the degree of government regulation of financial services, the extent of government influence in the financial sector through direct and indirect ownership, government influence on credit allocation, the degree of financial and capital market development, and the country's openness to foreign competition in the financial sector.

We complement these freedom-related variables listed above with three additional independent variables. Reporters Without Borders (RWB 2020) compiles the press freedom index (IV8). This index is based on a questionnaire that assesses six broad criteria, namely pluralism, media independence, media environment and self-censorship, legislative framework, transparency, and quality of infrastructure for news and information production and broadcasting, including the free flow of information on the Internet. This index moves in the opposite direction as that of the other indexes, namely, the higher the press index's score, the lower the press freedom.

Additionally, the Cato Institute (CI 2020) is a public policy research organization that compiles the 2019 Human Freedom Index (IV9). This index is an overall score based on seventy-six different indicators of personal, civil, and economic freedom including but not limited to the following areas: the size of government, legal system and property rights, access to sound money, freedom to trade internationally, regulations of credit, labor, and business. A narrower sub-index, also compiled by the Cato Institute, is the Personal Freedom Index (IV10). This sub-index quantifies specific personal freedoms like movement, religion, association, assembly, and civil society, expression and information, identity and relationships, the rule of law, and security and protection.

We analyze our data using generalized linear models, which are made up of a linear predictor $\eta_{i}=$ $\beta_{0}+\beta_{1} I V_{1 i}+\cdots+\beta_{p} I V_{p i}(1)$; and two functions, namely a link function that describes how the mean $E\left(D V_{i}\right)=\mu_{i}$, depends on the linear predictor $g\left(\mu_{i}\right)=\eta_{i}$; and a variance function that describes how the variance, $\operatorname{var}\left(D V_{i}\right)$ depends on the mean $\operatorname{var}\left(D V_{i}\right)=\phi V(\mu)$, where the dispersion parameter $\phi$ is a constant. In the case of the general linear model with $\epsilon=N\left(0, \sigma^{2}\right)$, we have the linear predictor $\eta_{i}$ specified above, the link function $g\left(\mu_{i}\right)=\mu_{i}$, and the variance function $V\left(\mu_{i}\right)=1$. In the case of a general binomial model $Y_{i} \sim \operatorname{Binomial}\left(n_{i}, p_{i}\right)$, to model the proportions $Y_{i} / n_{i}$, then $E\left(Y_{i} / n_{i}\right)=p_{i}$ and $\operatorname{var}\left(Y_{i} / n_{i}\right)=\frac{1}{n_{i}} p_{i}\left(1-p_{i}\right)$, and the variance function is $V\left(\mu_{i}\right)=\mu_{i}\left(1-\mu_{i}\right)$, and the link function must map from $(0,1) \rightarrow(-\infty, \infty)$. Two common choices for this function are $g\left(\mu_{i}\right)=\operatorname{logit}\left(\mu_{i}\right)=\log \left(\frac{\mu_{i}}{1-\mu_{i}}\right)$, and $\left(\mu_{i}\right)=\operatorname{probit}\left(\mu_{i}\right)=\Phi\left(\mu_{i}\right)$, where $\Phi$ is the cumulative distribution function.

We also use weighted least squares models to study the explanatory power of our independent variables over our dependent ones. When a model specification $D V_{i}=\beta_{0}+\beta_{1} I V_{1}+\beta_{2} I V_{2}+\ldots+\beta_{k} I V_{k}+u_{i}(2)$ has a heteroskedastic variance $\operatorname{var}\left(u_{i}\right)=\sigma_{i}^{2}$, we can divide each term by the weight $\omega_{i}=1 / \sigma_{i}$, to adjust the independent variables and transform the original equation into $\omega_{i} D V_{i}=\beta_{0} \omega_{i}+\beta_{1}\left(I V_{1} \omega_{i}\right)+\beta_{2}\left(I V_{2} \omega_{i}\right)+$ $\ldots+\beta_{\mathrm{k}}\left(I V_{k} \omega_{i}\right)+u_{i} \omega_{i}(3)$; which is the same as $D V_{i}^{*}=b_{o} X I V_{0 i}^{*}+b_{1} I V_{1 i}^{*}+b_{2} I V_{2 i}^{*}+\cdots+b_{k} I V_{k i}^{*}+u_{i}^{*}$ (4); but with homoscedastic variance $\operatorname{var}\left(u_{i}^{*}\right)=\operatorname{var}\left(u_{i} / \sigma_{i}\right)=\operatorname{var}\left(u_{i}\right) / \sigma_{i}^{2}=1$.. 


\section{EMPIRICAL RESULTS}

We classified our sample using our dependent variables from highest to lowest and identified the first (lowest) and fourth (highest) quartiles for each of them. A table with these results was not included in this article. However, we find that countries with the lowest government's daily average stringency indexes (37.48) have less than half the average of those with the highest indexes (81.9). Similarly, countries with the fastest COVID-19 response took an average of 27 days, while those without control of the outbreak have faced it during an average of 129 days until July 10, 2020. Likewise, those countries with the highest average of daily cases and deaths per million (0.55 and 0.02) have experienced about 120 times more cases and deaths per million than countries with the lowest averages (51.27 and 1.99). Correspondingly, those countries with the highest daily average of COVID-19 tests per thousand (0.031) have applied about 36 times more tests than those with the lowest averages (1.13).

Table 1 shows the independent sample tests of our independent variables for the first and fourth quartiles of our dependent variables obtained in the way we explained before. The statistically significant results show that countries of the lowest daily average stringency index (ceteris paribus) also have the highest economic, business, labor, monetary, trade, investment, financial, press, human, and personal freedoms as measured by their corresponding indexes. The significant results also show a similar outcome for the outbreak response time, but excluding financial freedom. These results suggest that, on average, those countries enjoying the highest degree of freedom did not impose strict restrictions on their citizens to control the first wave of COVID-19. However, these same countries were faster in controlling the outbreak than those with the lowest degrees of freedom.

Table 1 also contains statistically significant results showing that countries with the lowest daily average of cases and deaths per million (ceteris paribus) have the lowest economic, business, monetary, trade, investment, financial, human, and personal freedom measured by the corresponding indexes. Nevertheless, the press freedom index is significant only for the deaths per million, but this result is similar in that those countries with the lowest press freedom experience the lowest average daily deaths per million. These results suggest that those countries with the lowest degree of freedom experienced a less severe outbreak impact as measured by the daily average of cases and deaths per million.

Table 1 also shows that those countries with the lowest average daily tests per thousand (ceteris paribus) were the ones with the lowest economic, business, monetary, trade, investment, financial, press, human, and personal freedoms measured by the corresponding indexes. The table also shows marginally significant results regarding countries with high daily average tests per thousand and high labor freedom index, but these results are not significant at conventional levels of confidence. These results suggest that, on average, countries with the highest degrees of freedom have superior testing efforts.

These results are consistent with those previous studies mentioned before (Cepaluni et al. 2020, and Mazzucchelli et al. 2020.) To verify this consistency, we organized our sample by their 2019 Democracy Index compiled by the Economist's Intelligence Unit (TE-IU 2020), from lowest to highest, and determined the first (more democratic) and fourth (less democratic) quartiles. Table 2 shows the average values of our independent variables for each quartile. 
Table 1

Independent samples test results. Independent variables

\begin{tabular}{|c|c|c|c|c|c|c|c|c|c|c|}
\hline \multicolumn{11}{|c|}{ Daily average stringency index(DV1) } \\
\hline & IV1 & IV2 & IV3 & IV4 & IV5 & IV6 & IV7 & IV8 & IV9 & IV10 \\
\hline Q1 & 69.01 & 72.13 & 65.50 & 78.78 & 80.50 & 68.24 & 60.81 & 28.24 & 7.41 & 7.51 \\
\hline Q4 & 57.62 & 58.49 & 55.47 & 73.60 & 72.58 & 50.42 & 45.56 & 39.13 & 6.62 & 6.60 \\
\hline t-sta. & 4.66 & 3.82 & 3.02 & 3.46 & 3.46 & 3.83 & 3.58 & -3.38 & 3.59 & 2.98 \\
\hline p-val. & {$[0.00]^{* w+*}$} & {$[0.00]^{* a+2}$} & {$[0.003]^{* *+*}$} & {$[0.001]^{* * *}$} & {$[0.001]^{* * *}$} & {$[0.00]^{* a+x}$} & {$[0.001]^{* * *}$} & {$[0.001]^{* * *}$} & {$[0.001]^{* * *}$} & {$[0.004]^{*+*+}$} \\
\hline \multicolumn{11}{|c|}{ Outbreak response time (DV2) } \\
\hline & IV1 & IV2 & IV3 & IV4 & IV5 & IV6 & IV7 & IV8 & IV9 & IV10 \\
\hline Q1 & 66.69 & 69.52 & 62.54 & 78.31 & 78.93 & 68.05 & 55.61 & 26.72 & 7.30 & 7.50 \\
\hline Q4 & 61.07 & 63.85 & 57.12 & 74.98 & 73.53 & 55.50 & 50.50 & 35.41 & 6.70 & 6.69 \\
\hline t-sta. & 2.80 & 2.15 & 2.09 & 2.40 & 2.22 & 2.92 & 1.32 & -2.98 & 2.80 & 2.79 \\
\hline p-val. & {$[0.006]^{*+*}$} & {$[0.04]^{* *}$} & {$[0.04]^{* *}$} & {$[0.02]^{* *}$} & {$[0.03]^{* *}$} & {$[0.005]^{* * *}$} & [0.191] & {$[0.004]^{* * *}$} & {$[0.006]^{* * *}$} & {$[0.007]^{*+*}$} \\
\hline \multicolumn{11}{|c|}{ Average Daily Cases per Million (DV3) } \\
\hline & IV1 & IV2 & IV3 & IV4 & IV5 & IV6 & IV7 & IV8 & IV9 & IV10 \\
\hline Q1 & 57.41 & 57.48 & 60.91 & 73.00 & 70.28 & 47.75 & 41.00 & 38.40 & 6.44 & 6.31 \\
\hline Q4 & 67.27 & 71.91 & 61.90 & 78.21 & 79.53 & 66.83 & 60.00 & 33.22 & 7.25 & 7.26 \\
\hline t-sta. & -5.19 & -5.05 & -0.35 & -3.66 & -4.45 & -4.78 & -5.58 & 1.53 & -4.50 & -3.64 \\
\hline p-val. & {$[0.00]^{* * * *}$} & {$[0.00]^{* * * * *}$} & {$[0.728]$} & {$[0.00]^{* * * * *}$} & {$[0.00]^{* * * *}$} & {$[0.00]^{* * * * *}$} & {$[0.00]^{* * * * *}$} & {$[0.129]$} & {$[0.00]^{* * * * *}$} & {$[0.00]^{* * * *}$} \\
\hline \multicolumn{11}{|c|}{ Average Daily Deaths per Million (DV4) } \\
\hline & IV1 & IV2 & IV3 & IV4 & IV5 & IV6 & IV7 & IV8 & IV9 & IV10 \\
\hline Q1 & 61.16 & 64.24 & 59.40 & 73.12 & 71.12 & 53.51 & 46.22 & 35.62 & 6.63 & 6.51 \\
\hline Q4 & 67.47 & 70.57 & 59.28 & 78.06 & 81.05 & 71.22 & 62.97 & 28.92 & 7.36 & 7.53 \\
\hline t-sta. & -2.85 & -2.03 & 0.04 & -3.16 & -4.74 & -4.07 & -4.46 & 2.06 & -3.58 & -3.62 \\
\hline p-val. & {$[0.006]^{* * *}$} & {$[0.04]^{* *}$} & {$[0.968]$} & {$[0.02]^{* *}$} & {$[0.00]^{* * * * *}$} & {$[0.00]^{* * * * *}$} & {$[0.00]^{* * * * *}$} & {$[0.04]^{* *}$} & {$[0.001]^{* * *}$} & {$[0.001]^{* * *}$} \\
\hline \multicolumn{11}{|c|}{ Daily Average Tests per Thousand (DV5) } \\
\hline & IV1 & IV2 & IV3 & IV4 & IV5 & IV6 & IV7 & IV8 & IV9 & IV10 \\
\hline Q1 & 61.30 & 63.86 & 60.61 & 73.59 & 72.05 & 51.25 & 45.50 & 37.48 & 6.76 & 6.62 \\
\hline Q4 & 71.59 & 76.84 & 68.00 & 78.77 & 83.21 & 71.67 & 62.38 & 27.49 & 7.70 & 7.79 \\
\hline t-sta. & -3.92 & -3.44 & -1.71 & -2.63 & -4.06 & -3.51 & -3.00 & 2.34 & -3.71 & -3.15 \\
\hline p-val. & {$[0.00]^{* * * *}$} & {$[0.002]^{* * *}$} & {$[0.095]^{*}$} & {$[0.012]^{* *}$} & {$[0.00]^{* * * * *}$} & {$[0.001]^{* * *}$} & {$[0.005]^{* * * *}$} & {$[0.025]^{* *}$} & {$\left[0.0033^{* * *}\right.$} & {$[0.001]^{* * *}$} \\
\hline
\end{tabular}

Table 2 shows the independent samples tests of our independent variables for our sample of countries organized by their 2019 Democracy Index. The statistically significant results show that the countries with superior democracy indexes exhibit (ceteris paribus) superior economic, business, labor, monetary, trade, investment, financial, press, human, and personal freedom indexes. These results are consistent with those of Peev and Mueller (2012), who found that countries with democratic institutions are associated with higher economic freedoms.

Table 2

Independent samples test results. Independent variables comparison of countries by their 2019 democracy

\begin{tabular}{|c|c|c|c|c|c|c|c|c|c|c|}
\hline & IV1 & IV2 & IV3 & IV4 & IV5 & IV6 & IV7 & IV8 & IV9 & IV10 \\
\hline Q1 & 55.34 & 54.43 & 56.74 & 73.37 & 66.73 & 40.95 & 35.41 & 49.15 & 5.94 & 5.56 \\
\hline Q4 & 73.64 & 78.75 & 64.38 & 80.63 & 85.43 & 79.74 & 68.68 & 18.46 & 8.00 & 8.39 \\
\hline t-sta. & -10.30 & -7.93 & -2.59 & -4.99 & -9.84 & -11.09 & -9.83 & 11.96 & -13.64 & -15.23 \\
\hline p-val. & {$[0.00]^{* * * *}$} & {$[0.00]^{* * * *}$} & {$[0.01]^{* *}$} & {$[0.00]^{* * *}$} & {$[0.00]^{* * * *}$} & {$[0.00]^{* * * *}$} & {$[0.00]^{* * * *}$} & {$[0.00]^{* * * *}$} & {$[0.00]^{* * * *}$} & {$[0.00]^{* * * *}$} \\
\hline
\end{tabular}

Notes: ${ }^{* * * *},{ }^{* * *},{ }^{* *}$ and ${ }^{*}$ denote statistical significance at the $0.1 \%, 1 \%, 5 \%$, and $10 \%$ significance level, respectively. The same analysis was done using the logarithmic transformations of both the dependent and independent variables with the same results in terms of statistical significance. 
Table 3 shows our generalized linear regression models using the logarithmic weighted transformations of our dependent and independent variables. According to the results, the government's daily average stringency index has a negative relationship with the business freedom index. Besides, the outbreak response time has a negative and significant relationship with the monetary freedom index and the financial freedom index, but a positive and significant relationship with the press freedom index. The daily average of cases per million have a positive and significant relationship with the business freedom index, the monetary freedom index, and the financial freedom index, but a negative and significant relationship with the labor freedom index. Similarly, the daily average of deaths per million has a positive and significant relationship with the business, trade, and financial freedom indexes. Finally, no independent variable has significant explanatory power on the daily average of COVID-19 tests per thousand.

Table 3

Cross sectional analysis. Weighted least squares

\begin{tabular}{|c|c|c|c|c|c|}
\hline & LOG(DV1) & LOG(DV2) & LOG(DV3) & LOG(DV4) & LOG(DV5) \\
\hline $\begin{array}{l}\mathbf{C} \\
t \text {-sta. } \\
p \text {-val. }\end{array}$ & $\begin{array}{c}7.13 \\
5.48 \\
{[0.00]^{* * * *}}\end{array}$ & $\begin{array}{c}7.69 \\
2.67 \\
{[0.008]^{* * *}}\end{array}$ & $\begin{array}{c}-15.07 \\
-2.40 \\
{[0.02]^{* *}}\end{array}$ & $\begin{array}{c}-16.66 \\
-4.59 \\
{[0.00]^{* * * *}}\end{array}$ & $\begin{array}{c}-19.99 \\
-2.83 \\
{[0.006]^{* * *}}\end{array}$ \\
\hline $\begin{array}{l}\text { LOG(IV2) } \\
t \text {-sta. } \\
p \text {-val. }\end{array}$ & $\begin{array}{c}-0.24 \\
-1.77 \\
{[0.08]^{*}}\end{array}$ & & $\begin{array}{c}1.43 \\
1.99 \\
{[0.048]^{* *}}\end{array}$ & $\begin{array}{c}2.04 \\
2.28 \\
{[0.02]^{* *}}\end{array}$ & $\begin{array}{c}1.25 \\
1.13 \\
{[0.26]}\end{array}$ \\
\hline $\begin{array}{l}\text { LOG(IV3) } \\
t \text {-sta. } \\
p \text {-val. }\end{array}$ & $\begin{array}{l}-0.18 \\
-1.45 \\
{[0.15]}\end{array}$ & & $\begin{array}{c}-1.37 \\
-2.37 \\
{[0.02]^{* *}}\end{array}$ & & $\begin{array}{l}-0.18 \\
-0.27 \\
{[0.79]}\end{array}$ \\
\hline $\begin{array}{l}\text { LOG(IV4) } \\
t \text {-sta. } \\
p \text {-val. }\end{array}$ & $\begin{array}{l}-0.37 \\
-1.12 \\
{[0.27]}\end{array}$ & $\begin{array}{c}-1.29 \\
-1.94 \\
{[0.05]^{* *}} \\
\end{array}$ & $\begin{array}{c}2.83 \\
1.75 \\
{[0.08]^{*}}\end{array}$ & & $\begin{array}{c}2.67 \\
1.47 \\
{[0.14]}\end{array}$ \\
\hline $\begin{array}{l}\text { LOG(IV5) } \\
t \text {-sta. } \\
p \text {-val. }\end{array}$ & & & & $\begin{array}{c}1.64 \\
1.67 \\
{[0.097]^{* *}}\end{array}$ & \\
\hline $\begin{array}{l}\text { LOG(IV7) } \\
t \text {-sta. } \\
p \text {-val. }\end{array}$ & $\begin{array}{c}0.13 \\
1.49 \\
{[0.14]} \\
\end{array}$ & $\begin{array}{c}-0.26 \\
1.76 \\
{[0.08]^{*}} \\
\end{array}$ & $\begin{array}{c}1.04 \\
2.30 \\
{[0.02]^{* *}} \\
\end{array}$ & $\begin{array}{c}0.98 \\
2.48 \\
{[0.01]^{* *}}\end{array}$ & $\begin{array}{c}0.57 \\
1.11 \\
{[0.27]} \\
\end{array}$ \\
\hline $\begin{array}{l}\text { LOG(IV8) } \\
t \text {-sta. } \\
p \text {-val. }\end{array}$ & & $\begin{array}{c}0.32 \\
2.38 \\
{[0.02]^{* *}}\end{array}$ & & & \\
\hline $\begin{array}{l}\text { LOG(IV10) } \\
t \text {-sta. } \\
p \text {-val. }\end{array}$ & $\begin{array}{l}-0.12 \\
-0.77 \\
{[0.44]}\end{array}$ & & & & \\
\hline
\end{tabular}

Notes: $* * * *, * * *, * *$ and $*$ denote statistical significance at the $0.1 \%, 1 \%, 5 \%$, and $10 \%$ significance level, respectively. The table contains $t$-statistic and their corresponding $p$-values below in brackets. To avoid problems of multicollinearity, the variables IV9 and IV10 were included separately in the same regression models, but IV9 did not provide significant results, so these insignificant results were omitted in this report. We applied the Breusch-Pagan-Godfrey and the White tests for heteroskedasticity. The same models were also analyzed using generalized linear weighted models with the same significant results and signs, but these additional results were omitted in this article.

All these significant results of table 3 support those of table 1, except for the relation between the average of cases per million and the labor freedom, which is insignificant in table 1 . The other exception is the relationship between the outbreak response time and the financial freedom index, which is insignificant in table 1. Overall, these results suggest that countries with superior degrees of freedom experienced a more acute impact of the COVID-19 corroborated by a higher daily average of cases and deaths per million. This relation might be explained by the fact that these countries also did not impose strict restrictions compared with those with lower scores on their freedom indexes. However, these countries could control the first wave of the outbreak faster, as suggested by the shortest outbreak response time and the largest daily average of COVID-19 tests per thousand. 
Generalized Binomial Model (GBM) Results

\begin{tabular}{|l|c|c|c|c|c|c|c|c|}
\hline & C & IV2 & IV3 & IV4 & IV5 & IV6 & IV8 & IV10 \\
\hline \multirow{3}{*}{ LOGIT } & -51.76 & -0.16 & -0.03 & 0.35 & 0.21 & -0.04 & 0.11 & 2.23 \\
& -2.60 & -2.42 & -0.70 & 2.20 & 1.31 & -0.57 & 2.38 & 1.85 \\
& {$[0.01]^{* *}$} & {$[0.02]^{* *}$} & 0.48 & {$[0.03]^{* *}$} & 0.19 & 0.57 & {$[0.02]^{* *}$} & {$[0.06]^{*}$} \\
\hline \multirow{3}{*}{ PROBIT } & -27.14 & -0.08 & -0.02 & 0.19 & 0.10 & -0.02 & 0.07 & 1.16 \\
& -3.15 & -2.76 & -0.93 & 2.42 & 1.39 & -0.47 & 2.69 & 2.57 \\
& {$[0.002]^{* * *}$} & {$[0.01]^{* *}$} & 0.35 & {$[0.02]^{* *}$} & 0.16 & 0.64 & {$[0.01]^{* *}$} & {$[0.01]^{* *}$} \\
\hline
\end{tabular}

Notes: $* * *, * * *, * *$ and $*$ denote statistical significance at the $0.1 \%, 1 \%, 5 \%$, and $10 \%$ significance level, respectively. The table contains $z$-statistic and their corresponding $p$-values below in brackets.

Table 4 shows the results of our generalized binomial models using both logit and probit models. The significant results show that the probability of a country to succeed in controlling the first wave of COVID19 is negatively related to its business freedom index but positively related to its monetary freedom and press freedom. That probability also has a significant relationship with the personal freedom index but only in the probit model.

\section{DISCUSSIONS \& LIMITATIONS}

Table 1 shows that (ceteris paribus) countries with higher degrees of economic, business, labor, monetary, trade, investment, financial, press, human, and personal freedom indexes, failed at imposing severe restrictions to control the first wave of COVID-19. As a result, these freer countries (excluding labor freedom) suffered a more severe impact of the outbreak measured by the daily average of cases and deaths per million. However, these same countries with higher scores of freedom indexes were more effective at controlling the first wave of COVID-19 confirmed by a shorter outbreak response time (excluding the financial freedom index) and a higher daily average of COVID-19 tests per thousand (excluding the labor freedom index).

The results of table 3 suggest that business freedom has a significant positive effect on the severity of the outbreak's impact measured by the daily average of cases and deaths per million. The table also shows that this index has a significant negative impact on a country's response to the pandemic as measured by the government's daily average stringency index. Indeed, countries with excellent business freedom and no business constrains by national governments face significant challenges to impose business restrictions to control the COVID-19. The resistance of a country's business sector to control measures like business lockdowns results in higher average daily cases and deaths per million. These results are consistent with that of Díaz-Casero et al. (2012), who find that almost all components of the Economic Freedom Index have a significant relationship with the entrepreneurial activity.

Table 3 also shows that the monetary freedom index has a significant negative impact on a country's response speed to the COVID-19 measured by the outbreak response time, but a significant positive effect on the harshness of the outbreak measured by the daily average of cases per million. Indeed, during the first months of the outbreak, countries worldwide experienced shortages and price spikes of many goods. These price increases and shortages were the direct consequence of frozen factories, crops rotting in fields, international supply chain disruptions, etcetera. A representative example was the call of the World Health Organization (2020, March) asking for industry and government action to control rising demand, panic buying, speculation, and hoarding, particularly for medical supplies. Countries enjoying great monetary freedom during the pandemic experienced a significant hardship implementing controls aimed to avoid distortions in the market place caused by the COVID-19. These difficulties resulted in slower response 
times and a more significant number of cases. For countries with low monetary freedom, the control of distortions in the marketplace was easier, resulting in faster response time and lower cases.

Table 3 also shows that the financial freedom index has a significant positive relationship with the daily average of cases and deaths per million, but a negative and significant relationship with the outbreak response time. The impact of the COVID-19 on financial institutions has resulted in many challenges, including defaults on credit cards, loans, mortgages, etcetera. As a result, most central banks worldwide have implemented guidelines and regulations to help financial institutions deal with these challenges. Let us consider the case of the US, a country with a tremendous financial freedom index. On August 3, 2020, the Federal Financial Examination Council (FFEC 2020) issued a set of guidelines suggesting financial institutions 'work prudently' with borrowers who may be unable to honor their payment obligations due to the COVID-19. Similarly, the Board of Governors of the Federal Reserve (BGFD 2020) issued a regulatory action related to COVID-19, where it 'encourages' financial institutions to 'work constructively' with borrowers affected by COVID-19.

China is an example of a country with a low financial freedom index. Ali (2020) informs that four of the first five largest banks in the world by total assets are state-owned Chinese banks. Besides, Chong (2020) informed that China has engaged in a massive forbearance effort coordinated by regulators and banks to deal with a wave of COVID-19-related defaults. Accordingly, Chinese companies and individuals were allowed to defer loan principal and interest payments until June 30, 2020. These two examples contrast the prospects of US borrowers hoping to work 'constructively' with their lenders in the middle of the outbreak, versus the certainty of the forbearance efforts implemented by the Chinese regulators. Certainly that any government efforts to control COVID-19, including lockdown of business, will face a higher resistance in the US than in China, at least from a borrowers' perspective. Therefore, countries with low financial freedom and controls intended to reduce the financial burden on individual and business borrowers will find less resistance at implementing lockdown restrictions and, in turn, lower daily average of cases and deaths per million.

Regarding the more prolonged outbreak response time in countries with superior financial freedom, the explanation comes from the difference between private and public financial institutions in terms of efficiency. Indeed, Cull, Martinez, and Verrier (2018) state that the agency costs in state-owned banks lead to operational inefficiencies and low intermediation quality, especially in developing countries. Similarly, Chortareas, Girardone, and Ventouric (2013) find a positive and significant relationship between an economy's financial freedom and banks' cost advantages and overall efficiency, especially in countries with freer political systems.

Table 3 also shows that the labor market freedom has a significant and negative relationship with the daily average of cases per million. Countries with high scores on labor freedom have experienced a substantial increase in unemployment rates than those with low labor freedom scores. State intervention and government controls over the labor market reduce the labor freedom index. These actions are precisely what many countries have been doing to minimize the negative impact of COVID-19 on their national labor markets. According to the Organization for Economic Co-operation and Development (OECD 2020), a large number of countries have implemented a wide range of policies to preserve existing jobs, such as job retention schemes and administrative suspensions of dismissals. They find that those countries with a large proportion of their labor market covered by these policies have experienced smaller increases in unemployment rates between early March and end-April 2020, compared to countries with narrower policies' scope and budget. Countries with high unemployment rates resulting from low government intervention in the labor market (high labor market freedom) have faced significant challenges at persuading people to stay at home. Contrary, countries that implemented broad policies and regulations to protect their 
national labor markets have experienced better acceptance of restrictions aimed at controlling the first wave of COVID-19 and, in turn, a lower daily average of cases per million.

Table 3 also shows a positive and significant relationship between the daily average of deaths per million and the trade freedom index. Indeed, on April 23, 2020, the World Trade Organization (WTO $2020 \mathrm{~b}$ ) reported that a growing number of export prohibitions and restrictions were introduced by many countries to mitigate critical shortages of food and medical supplies. These restrictions reduced trade freedom and allowed many countries to secure their existing medical supplies and reduce their daily average of deaths per million (WHO 2020a). Finally, table 3 also shows a positive and significant relationship between the outbreak response time and the press freedom index. Countries with superior press freedom enjoy many benefits, but also a significant challenge, namely fake news. Indeed, the World Health Organization (WHO 2020, May) joined the UK government in the awareness campaign called 'Stop The Spread', which aimed to raise awareness about the risks of misinformation around COVID-19. Fake news and misinformation on the outbreak in social media has been a challenge for countries with greater press freedom. Therefore, those countries with media restrictions and poor press freedom, particularly those censoring fake news and misinformation flowing on the Internet, have a shorter outbreak response time.

Finally, table 4 shows that the probability of a country to control the first wave of COVID-19 is negatively and significantly related to the business freedom index. The rationale to explain this relationship is the same as that described above. Countries with superior business freedom face significant difficulties in imposing restrictions on business operations aimed at controlling the outbreak. Similarly, table 4 shows that the probability for a country to control the outbreak is positively and significantly related to the monetary, press, and personal freedom indexes. The rationale to explain these relationships are the same as those described above. Countries with great monetary freedom experience severe difficulties in imposing market controls aimed to avoid price distortions caused by the COVID-19. Likewise, countries with excellent press freedom and severe problems of outbreak-related misinformation, particularly fake news flowing on the Internet, have a longer outbreak response time. Finally, the positive relationship between the probability of controlling the first wave of COVID-19 and the personal freedom index can be explained by the consistency with previous studies (Cepaluni et al. 2020, Dempere 2021, and Mazzucchelli et al. 2020.) Indeed, we confirmed on table 2 that countries with higher democracy indexes, and therefore higher personal freedom, have a much better probability of controlling the first wave of COVID-19.

Regarding the limitations of this study, we can mention that our dependent variables do not enjoy universal consensus as valid metrics to study countries' effectiveness to control the first wave of COVID19. Regarding our independent variables, a similar limitation arises. For example, the Heritage Foundation (HF 2020) and the Fraser Institute are the most quoted sources of economic freedom. However, Ram (2014) finds that country rankings on the two sources show significant differences in several cases and warns that users should exercise caution in drawing inferences when using these classifications. Therefore, repeating our analysis using data from the Fraser Institute might produce different results.

Finally, Morris and Reuben (2020) also identify several limitations when trying to make an international comparison of the outbreak. They mention differences in how countries record COVID-19 deaths, differences in testing efforts, differences in health services, possible unreliable data from countries with tightly controlled political systems, and many demographics variables affecting the pandemic spread like average age, population density, urban versus rural population, age structure, etcetera. 


\section{CONCLUSIONS}

This study tries to identify some country-specific economic freedom-related factors with explanatory power at the success in controlling the first wave of COVID-19 outbreak. Our sample of one hundred and fifty-six countries suggests that those with superior economic, business, labor, monetary, trade, investment, financial, press, human, and personal freedom exhibited (ceteris paribus) the lowest daily average stringency index. These same countries also exhibit the quickest response time and the highest daily average of tests per thousand, but excluding financial and labor freedom. We also find that countries with superior degrees of freedoms suffered a more severe impact of the outbreak as measured by the daily average of cases and deaths per million (excluding the labor freedom). However, these countries were more effective in controlling the first wave of COVID-19 as measured by the shorter outbreak response time (excluding the financial freedom index) and a higher daily average of COVID-19 tests per thousand (excluding the labor freedom index).

We also find a positive and significant relationship between a country's business, monetary, and financial freedom indexes and its daily average of cases and deaths per million; and between a country's press freedom and its outbreak response time. We also find a negative and significant relationship between a country's monetary freedom and its pandemic response time, and between a country's labor market freedom and its daily average of cases per million. We also find significant results showing that the probability of a country to succeed in controlling the first wave of COVID-19 has a negative relationship with its business freedom index, but a positive one with its monetary freedom and press freedom.

Our results suggest that during the early stages of the COVID-19 crisis, countries with superior business freedom may have experienced significant resistance from business entities to governmentimposed restrictions. Similarly, governments of countries with high monetary freedom may have faced difficulties implementing controls to minimize market distortions caused by the pandemic. Likewise, financial regulators (e.g., central banks) in countries with a high degree of financial freedom may have endured problems trying to modify the conditions of lender-borrower relationships during the beginning of the outbreak. The lack of quick and significant changes in the creditor-debtor relationship may have placed pressure on borrowers to continue performing their economic activities with minimum interference from any restrictive government policy. Correspondingly, governments in countries with low scores of labor freedom may have imposed government controls over the labor market more quickly to preserve existing jobs and minimize the population's economic hardship resulting from policies like lockdowns or business closures. Nations with high unemployment rates resulting from low government intervention in the labor market may have faced significant challenges encouraging people to stay at home.

Equally, our results suggest that countries with inferior trade freedom may have imposed trade restrictions quickly to protect their existing medical supplies and reduce their daily average of COVID-19 deaths per million. In the same way, countries with superior press freedom face the challenge of fake news. The WHO (2019) has highlighted public health communication and community engagement as vital government health policies. Notably, the $\mathrm{WHO}$ has cautioned about the risk of infodemic defined as the COVID-19 information overload (some accurate and some fake), making it problematic for people to recognize truthful sources of information and dependable guidance when needed. Our results suggest that countries with media restrictions and poor press freedom may have quickly censored fake news and misinformation flowing on the Internet, resulting in a shorter outbreak response time. 


\section{REFERENCES}

Ali, Z. (2020). The world's 100 largest banks, 2020. S\&P Global Market Intelligence, Retrieved August 1, 2020 from https://www.spglobal.com/marketintelligence/en/news-insights/ latest-news-headlines/the-world-s-100largest-banks-2020-57854079

Alon, I., Farrell, M., \& Li, S. (2020). Regime Type and COVID-19 Response. FIIB Business Review. https://doi.org/10.1177/2319714520928884

BGFD - Board of Governors of the Federal Reserve (2020). Coronavirus Disease 2019 (COVID-19). Supervisory and Regulatory Actions in response to COVID-19. Retrieved July 21, 2020 from https://www.federalreserve.gov/supervisory-regulatory-action-response-covid-19.htm

Bjørnskov, C. (2016). Economic freedom and economic crises. European Journal of Political Economy, 45(1), 11-23. https://doi.org/10.1016/j.ejpoleco.2016.08.003

Cepaluni, G., Dorsch, M., \& Branyiczki, R. (2020). Political Regimes and Deaths in the Early Stages of the COVID19 Pandemic. Working Paper, Retrieved August 9, 2020 from https://papers.ssrn.com/sol3/Delivery.cfm/ SSRN_ID3586767_code1637950.pdf?abstractid=3586767\&mirid=1

CI - CATO Institute (2020). Human Freedom Index. Retrieved August 10, 2020 from https://www.cato.org/humanfreedom-index-new

Chong, K. P. (2020). A \$100 Billion Breather: China Banks Give Borrowers a Coronavirus Debt Holiday, Payment suspensions allow many companies to stay solvent, and they delay the day of reckoning for the country's lenders. Wall Street Journal (Online). Retrieved August 2, 2020 from https://search-proquestcom.ezproxy.hct.ac.ae/docview/2391399046?pq-origsite $=$ summon

Chortareas, G. E., Girardone, C., \& Ventouric, A. (2013). Financial freedom and bank efficiency: Evidence from the European Union.' Journal of Banking \& Finance, 37(4), 1223-1231. Retrieved August 3, 2020 from https://doi.org/10.1016/j.jbankfin.2012.11.015

Cull, R., Martinez, M., \& Verrier, J. (2018). Bank Ownership. Trends and Implications. World Bank Group - Policy Research Working Paper $\quad 8297 . \quad$ Retrieved August $\quad 5, \quad 2020$ from http://documents1.worldbank.org/curated/en/810621515444012541/pdf/WPS8297.pdf

Dempere, J. (2021). A Recipe to Control the First Wave of COVID-19: More or Less Democracy? Transforming Government: People, Process, and Policy. Retrieved November 12, 2021 from https://www.emerald.com/insight/content/doi/10.1108/TG-08-2020-0206/full/html

Díaz-Casero, J., Díaz-Aunión, D., Sánchez-Escobedo, M., Coduras, A., Hernández-Mogollón, R. (2012). Economic freedom and entrepreneurial activity.' Management Decision, 50(9), 1686-1711. Retrieved August 5, 2020 from https://doi.org/10.1108/00251741211266750

Erdem, O. (2020). Freedom and stock market performance during Covid-19 outbreak. Finance Research Letters, Retrieved August 5, 2020 from https://doi.org/10.1016/j.frl.2020.101671

FFIE - Federal Financial Institutions Examination Council (2020). Join Statement on Additional Loan Accommodation Related to COVID-19. Retrieved August 5, 2020 from https://www.occ.gov/news-issuances/bulletins/2020/bulletin2020-72a.pdf

Hannah, R., Ortiz-Ospina, E., Beltekian, D., Mathieu, E., Hasell, J., Macdonald, B., Giattino, C., \& Roser, M. (2020). Statistics and Research. Coronavirus Pandemic (COVID-19), Our World in Data. Retrieved July 10, 2020 from https://ourworldindata.org/coronavirus

Herren, C., Brownwright, T., Liu, E., El Amiri, N., \& Majumder, M. (2020). Democracy and Mobility: A preliminary analysis of global adherence to non-pharmaceutical interventions for COVID-19.' Working Paper. Retrieved August 5, 2020 from https://papers.ssrn.com/sol3/Delivery.cfm/SSRN_ID3570206_code4099104. pdf?abstractid $=3570206 \&$ mirid $=15$

ILO - International Labor Organization (2020). ILO Monitor: COVID-19 and the world of work. Fourth edition. Updated estimates and analysis. Retrieved August 5, 2020 from https://www.ilo.org/wcmsp5/groups/public/--dgreports/---dcomm/documents /briefingnote/ wcms_745963.pdf

Lambert, L. (2020). The coronavirus has now killed more Americans than every war since the start of the Korean War-combined. Fortune. Retrieved August 5, 2020 from https://fortune.com/2020/06/10/coronavirusdeaths-us-covid-19-killed-more-americans-korean-war-vietnam-iraq-persian-gulf-combined-how-many-died/ 
Mazzucchelli, R., Agudo, A., Dieguez, E., \& Crespí, N. (2020). Democracy and Covid-19 mortality in Europe. Revista Española de Salud Pública, 94(1), 1-9. Retrieved August 7, 2020 from https://www.researchgate.net/publication/342448913_Democracy_and_Covid-19_mortality_in_Europe

Morris, C. and Reuben, A. (2020). Coronavirus: Why are international comparisons difficult?' BBC News. Retrieved August 7, 2020 from https://www.bbc.com/news/52311014

OECD - Organization for Economic Co-operation and Development (2020). OECD Economic Outlook, 2020 (1), OECD Publishing. Retrieved August 5, 2020 from https://doi.org/10.1787/0d1d1e2e-en

Peev, E. and Mueller, D. (2012). Democracy, Economic Freedom and Growth in Transition Economies. Ky/klos, 65(3), 371-407. Retrieved August 7, 2020 from https://doi.org/10.1111/j.1467-6435.2012.00543.x

Ram, R. (2014). Measuring economic freedom: a comparison of two major sources. Applied Economics Letters, 21(12), 852-856. Retrieved August 7, 2020 from https://doi.org/10.1080/13504851.2014.894620

RWB - Reporters Without Borders (2020). 2020 World Press Freedom Index. Retrieved July 10, 2020 from https://rsf.org/en/ranking

TE-IN, The Economist - Intelligence Unit (2020) Democracy Index 2019. Retrieved July 15, 2020 from https://www.eiu.com / topic/ democracy-index

HF - Heritage Foundation (2020). Index of Economic Freedom. Retrieved July 10, 2020 from https://www.heritage.org/index/

WB - World Bank (2020). The Global Economic Outlook During the COVID-19 Pandemic: A Changed World. Retrieved August 7, 2020 from https://www.worldbank.org/en/news/ feature/2020/06/08/the-global-economicoutlook-during-the-covid-19-pandemic-a-changed-world

UN - United Nations (2020). COVID-19 response. Launch of the Policy Brief: Education during COVID-19 and Beyond. 'The future of education is here.' Retrieved July 25, 2020 from https://www.un.org/en/coronavirus/future-educationhere

Yevdokimov, Y., Melnyk, L., Lyulyov, O., Panchenko, O., \& Kubatko, V. (2018). Economic Freedom and Democracy: Determinant Factors in Increasing Macroeconomic Stability. Problems and Perspectives in Management, 16(2), 279290. http://dx.doi.org/10.21511/ppm.16(2).2018.26

WHO - World Health Organization (2019). Novel Coronavirus (2019-nCov). Situation Report - 13. Retrieved November 12 , 2021 from https://www.who.int/docs/default-source/coronaviruse/situation-reports/20200202-sitrep-13ncov-v3.pdf

WHO - World Health Organization (2020a). Shortage of personal protective equipment endangering health workers worldwide. Retrieved August 7, 2020 from https://www.who.int/news-room/detail/03-03-2020-shortage-of-personalprotective-equipment-endangering-health-workers-worldwideWHO - World Health Organization (2020b). Countering misinformation about COVID-19. A joint campaign with the Government of the United Kingdom. Retrieved August 7, 2020 from https://www.who.int/news-room/feature-stories/detail/countering-misinformationabout-covid-1

WTO - World Trade Organization (2020). Export Probibitions and restrictions. Information Note. Retrieved August 7, 2020 from https://www.wto.org/english/tratop_e/covid19_e/ export_prohibitions_report_e.pdf 